\title{
Thermal Solvolysis of Coals Under Mild Conditions as an Alternative Way to Produce Aromatics for Carbon Materials
}

\author{
Peter Kuznetsov ${ }^{1,5,}$, Budeebazar Avid ${ }^{2}$, Lyudmila Kuznetsova $^{1}$, \\ Barnazan Purevsuren ${ }^{2}$, Xing Fan ${ }^{3}$, Zinfer Ismagilov ${ }^{4}$, and Vladimir Safin ${ }^{1,5}$. \\ ${ }^{I}$ Institute of Chemistry and Chemical Technology SB RAS, Federal Research Center "Krasnoyarsk Science \\ Center SB RAS”, Krasnoyarsk, Russia \\ ${ }^{2}$ Institute of Chemistry and Chemical Technology, Mongolian Academy of Sciences, Ulaanbaatar, Mongolia \\ ${ }^{3}$ College of Chemical and Biological Engineering, Shandong University of Science and Technology, Qingdao, \\ Shandong, China \\ ${ }^{4}$ Institute of Coal Chemistry and Material Science SB RAS, Federal Research Center "Coal and Coal \\ Chemistry”, Kemerovo, Russia \\ ${ }^{5}$ Institute of Petroleum and Gas, Siberian Federal University, Krasnoyarsk Russia \\ *Corresponding author. Email: kpn@icct.ru.
}

\begin{abstract}
Russia, China and, Mongolia are among the countries having large reserves of coals which are traditionally utilized mainly as a fuel for energy generation. In the present paper, the solvolysis of a large series of differentranked coals from various deposits of Russia and Mongolia in anthracene oil as a solvent to produce soluble aromatic substances was studied. All the coal samples were well characterized by the data on the chemical composition and on the conventional classification industrial indexes. The correlations between the composition and properties of coals and their reactivity for pyrolysis and for solvolysis with anthracene oil into soluble products were analyzed. Well defined correlations were established between the coal conversion into quinoline solubles and the properties of coals such as vitrinite reflectance, the yield of volatile matter, carbon content, and temperature at which the main decomposition occurs during coal pyrolysis. The criteria for the properties of coals suitable for solvolytic conversion into soluble aromatic substances are suggested. The chemical and group composition and the characteristics of the molecular structure of the soluble products obtained were studied using chemical and ${ }^{1} \mathrm{H}$ and ${ }^{13} \mathrm{C}$ NMR techniques. The extract obtained can serve as an alternative source for aromatics, liquid fuels, and for the production of a substitute for coal-tar pitch binder and for other purposes.
\end{abstract}

Keywords: Coal, Pyrolysis, Solvolysis, Correlation, Aromatics

\section{INTRODUCTION}

Russia, China, and Mongolia are among the countries having large reserves of coals which are traditionally utilized mainly as a fuel for energy generation. The high-temperature coal coking to produce metallurgical coke is the second large-scale process of coal utilization in China and in Russia. This process is an inherent part of the integrated production of iron and steel where both at present and centuries ago traditional blast furnace technology using indispensable metallurgical coke dominates [13]. The key challenge of the blast furnace technology development is a radical decrease in the specific consumption of coke because of its high cost (its production accounts for almost half of all costs for metal production), significant $\mathrm{CO}_{2}$ emission, and limited resources of high-quality coking coals $[1,2]$. 
During the last decades, the specific coke consumption in blast furnaces has been reduced tremendously due to technological innovations. An increase in the number of blast furnaces with an injection of pulverized coal, oil fractions, and natural gas (for partial replacement of coke), and also largescale development of the alternative steelmaking technologies without coke will lead to a further decrease in demand for metallurgical coke.

However, the coal coking yields also coal tar (CT) as a minor by product $(3-5 \%)$ which is a valuable feedstock for aromatics needed in the production of advanced carbon materials and composites for a wide range of applications [4]. The predominant part of CT is consumed to produce coaltar pitch (CTP) as a binder agent in the anode manufacturing for the aluminum electrolysis [5]. However, the supply of CTP of the required quantity is becoming more uncertain. Currently, a significant shortage in CTP availability takes place in most countries, except for China. It is appropriate to add here that the rapidly developing steelmaking technology with electric arc furnaces also needs CTP for graphite electrode manufacturing. So, an alternative supply of pitch binder is required to supplement, or eventually replace, CTP. The opposite trends in the production and consumption of CT and CTP are a growing concern to the availability of polyaromatic chemicals for manufacturing various carbon materials. The need to solve this challenge is reasoned also by a significant drawback of the commercial CT and CTP because of their carcinogenicity.

The thermal dissolution of coal at mild conditions (in terms of temperature and pressure) is a promising alternative way for producing substitutes for CT [6]. In review papers devoted to the analysis of the results published over the past decade [7-9], it was noted that the efficiency of low temperature coal dissolution depends in a complex way on many factors: process conditions, composition, and properties of coals and solvents, etc. Iino et al. [10] studied the thermal dissolution of 56 coal samples in a binary solvent containing carbon disulfide and N-methyl-2pyrrolidinone. The correlation between the extract yield and carbon content in coals was found. However, Mochida et al. [11] reported that the yield of solubles from the coal dissolution in pyrene solvent ranged from $20 \%$ to $93 \%$ irrespectively of coal rank. On the other hand, Griffith et al. [12] reported linear correlations between the coal dissolution in recycled light oil and the contents of Vdaf and Cdaf. According to Rahman et al. [8], the dissolution of coals in a light gas cycle oil and in its mixture with a polar co-solvent at $350^{\circ} \mathrm{C}$ depended largely on the oxygen concentration in the coals.

The thermal dissolution of coals depending on their plasticity was also studied [11-14]. Mochida et al. [11] showed the effect of Ts softening point on the coal dissolution to depend on the properties of the solvent used. On coal dissolution in a pyrene solvent at $390^{\circ} \mathrm{C}$, an increase in $\mathrm{Ts}$ from 360 to $420^{\circ} \mathrm{C}$ resulted in decreasing yield of soluble products. On the other hand, no effect of Ts was observed in coal dissolution with a more efficient solvent capable of solvolysis of chemical bonds in coal. Koyano et al. [15] attempted to establish correlations using a large array of data accumulated in the course of searching active coals for the production of Hyper Coal [13, 14, 16]. The data for 76 coal samples showed large variation in the extract yields $(14 \%$ to $82 \%)$ in the 1 methylnaphthalene solvent at $360-370^{\circ} \mathrm{C}$. However, no significant correlations with the traditional coal indexes such as carbon, hydrogen, and oxygen contents and the yield of volatile matter were found. Some correlations were revealed (with the determination coefficients of $\mathrm{R}^{2}=0.59$ ) only for a limited set of coals using combinations of characteristics, such as $\mathrm{V}^{\mathrm{daf}} / \mathrm{O}^{\mathrm{daf}}$ and $\mathrm{C} / \mathrm{H}_{\mathrm{at}}$ ratios. The authors [17] studied the dissolution of different coals in tetralin and in anthracene oil at $380^{\circ} \mathrm{C}$. Subbituminous coals were found to show maximum reactivity in the tetralin medium, however, bituminous coals were the most reactive in the anthracene oil. The dissolution of bituminous coal using various industrial hydrocarbon fractions of coal and petroleum origins as solvents was also studied $[18,19]$. Anthracene oil was found to be the most efficient solvent for coal conversion into quinoline solubles.

In general, from the analysis of the results published, it follows that coal dissolution at mild temperatures is in a complex dependence on the properties of both coals and solvents. The conclusions made by different authors are often contradictory; this may be due to a difference in the reaction conditions, to the limited number of coal samples used, to different methods for determining the process indexes, and to the specificity of interactions of the poly functional fragments of coal with solvent molecules, the nature of which is poorly understood. Many publications provided incomplete information on the properties of coals and solvents used, and on the reaction conditions, and this complicates the analysis of the data published.

In this paper, we present the results of a systematic study aimed at finding the relationships 
between the chemical and physical properties of coals and the yields of quinoline-soluble extracts using anthracene oil as a solvent. The properties of the quinoline-soluble extracts produced were characterized by various techniques.

\section{EXPERIMENTAL}

\subsection{Sample Preparation}

A fairly large and regular series of coal samples of different ranks were used in this study. They were selected from different deposits in Russia (Kuznetsk basin, Kansk-Achinsk brown coal basin, Irkutsk basin, and Kaa-Khem and Chadan deposits) and in Mongolia (Baganuur, Shive Ovoo, Tavantolgoi, and Nariin-Sukhait deposits). The coals were selected so to cover a wide range of composition, properties, and rank from typical brown coals to low-volatile bituminous coals. In total, this coal series included 18 coal samples.

\subsection{Petrographic and Thermodynamic Analysis}

The coals were dried and analyzed using conventional standard procedures and techniques. The ultimate analysis was performed on a Flash EATM 1112 analyzer. The oxygen content was calculated by difference. Petrographic analysis was performed using a SIAMS-620 automated system in oil immersion. The ability of the coals to become fluid during heating in the absence of air was evaluated by the thickness of the plastic layer derived from the 'plastometric curve' according to Sapozhnikov method [20]. The softening point of the pitch-like extracts produced was determined using a "ring and ball" method. Thermogravimetric analysis of coals was carried out on an STA 449 F1 Jupiter thermal analyzer (NETZSCH, Germany) in corundum crucibles in an argon flow. The ${ }^{1} \mathrm{H}$ NMR and ${ }^{13} \mathrm{C}$ NMR spectra were recorded for the chloroform-d dissolved fractions using a Bruker Avance III Fourier spectrometer.

\subsection{Thermal Dissolution}

Thermal dissolution of coals was carried out in the stainless steel rotating $80 \mathrm{~mL}$ autoclaves and in a $2 \mathrm{~L}$ autoclave equipped with a mechanical stirrer. The anthracene oil (AO) was used as a solvent. The autoclave loaded with coal-solvent slurry $(33 \%$ of coal), was purged carefully with nitrogen and hermetically sealed. The $80 \mathrm{~mL}$ autoclaves (three units simultaneously) were placed in a rotating sand bath heated by an electric furnace at a required reaction temperature and at 1.5-2.0 $\mathrm{MPa}$ of autogenous pressure. At reaction completion, the autoclaves were cooled during rotation. The gas was collected and analyzed by gas chromatography. The main product was quantitatively removed from the autoclave, transferred to a paper filter, and subjected to Soxhlet extraction with toluene. The tolueneinsoluble residue was exhaustively extracted with a hot quinoline, washed with heptane for complete extraction of quinoline, dried, and weighed, and the ash content was determined. The larger scale (typically $900 \mathrm{~g}$ ) tests with $2 \mathrm{~L}$ autoclave were required in order to prepare coal extract for comprehensive characterization of the composition and properties. The rotation of the sand bath with small autoclaves (80 rpm of rotation) and mechanical stirrer (150 rpm speed) ensured efficient stirring of the reaction mixture and gradientless reaction conditions in terms of temperature and concentrations of the reactants.

The conversion of coals and the yield of soluble products were determined from a change in the ash content of the residues after extractions with quinoline. Usually, two to three tests on the dissolution were carried out, the discrepancies in conversion did not exceed $3 \%$. The average values are given in the paper.

\section{RESULT AND DISCUSSION}

\subsection{The Characterization of the Composition of Solvent and Coals}

The anthracene oil (AO) had the following elemental composition (wt \%): carbon, 87.6; hydrogen, 5.2; and nitrogen, oxygen, and sulfur 7.2 in total. On temperature-programmed heating, the release of volatile substances began at about $150^{\circ} \mathrm{C}$, and a maximum rate of weight loss was observed at 290-295 ${ }^{\circ}$.

Table 1 summarizes the ultimate analysis data for all coals samples. The carbon content ranged 70.9 to $90.0 \%$, oxygen 23.1 to $2.0 \%$. The coals had relatively low sulfur and nitrogen contents and a small amount of mineral matter (less than $10 \%$, except for two samples), which minimized the possible influence on coal behavior during the thermal dissolution process.

Shown in Table 2 are the analytical data which reflect the chemical, physical and technical properties of coals. All the coal samples were of the vitrinite type with a vitrinite content of more than $70 \%$ 
(except for two high-rank KB7 and KB8 samples with vitrinite contents of 61 and $60 \%$, respectively). The values of the Ro.r vitrinite reflectance range 0.41 to $1.47 \%$. The brown coals and subbituminous coals exhibit no plasticity, the bituminous coals showed selected for this study can be qualified as a wellcharacterized one of predominantly vitrinite type and plasticity with the plastic layer thickness of up to 30 $\mathrm{mm}$. In general, the characteristics of the chemical and chemical-technological indicators of coals shown in Table 1 and Table 2 are in good agreement with each other. Thus, the series of coal samples differed with rank from brown coals to low volatile bituminous coals.

Table 1. The list of selected coals and the results of the ultimate analyses

\begin{tabular}{|c|c|c|c|c|c|c|c|c|}
\hline \multirow{2}{*}{$\begin{array}{l}\text { Coal } \\
\text { code }\end{array}$} & \multirow{2}{*}{$\begin{array}{c}\text { Rank } \\
\text { category* }\end{array}$} & \multirow{2}{*}{ Deposit or mine } & \multicolumn{5}{|c|}{ Elemental composition, wt \% on a $d a f$ basis } & \multirow[t]{2}{*}{$\mathbf{H} / \mathbf{C}_{\mathrm{at}}$} \\
\hline & & & $\mathbf{C}$ & $\mathbf{H}$ & $\mathbf{N}$ & $\mathbf{S}$ & $\mathbf{O}$ & \\
\hline \multicolumn{9}{|c|}{ Coals from East Siberia Basins } \\
\hline ES1 & $\mathrm{L}$ & Latyntsevo & 72.0 & 5.1 & 1.1 & 0.3 & 21.5 & 0.85 \\
\hline ES2 & $\mathrm{L}$ & Borodino & 71.0 & 4.9 & 0.7 & 0.3 & 23.1 & 0.83 \\
\hline ES3 & S-B & Cheremkhovo & 76.2 & 5.5 & 1.4 & 0.7 & 16.2 & 0.87 \\
\hline ES4 & S-B & Sayano-Partizansk & 75.7 & 5.1 & 1.7 & 0.6 & 17.5 & 0.81 \\
\hline \multicolumn{9}{|c|}{ Coals from Tyva Basins } \\
\hline RT1 & $\mathrm{B}-\mathrm{C}$ & Kaa-Khem & 78.0 & 6.2 & 1.2 & 0.3 & 14.7 & 0.95 \\
\hline RT2 & $\mathrm{B}-\mathrm{C}$ & Chadan & 84.7 & 5.5 & 1.3 & 0.6 & 7.9 & 0.78 \\
\hline \multicolumn{9}{|c|}{ Coals from Kuznetsk Basin } \\
\hline KB1 & $\mathrm{B}-\mathrm{C}$ & Polysaevskaya mine & 82.9 & 6.0 & 2.3 & 0.3 & 8.5 & 0.87 \\
\hline KB2 & B-C & Uskovskaya mine & 85.4 & 5.9 & 1.1 & 0.3 & 7.3 & 0.83 \\
\hline KB3 & $\mathrm{B}-\mathrm{C}$ & Raspadskaya mine & 86.6 & 5.7 & 1.0 & 0.7 & 6.0 & 0.79 \\
\hline KB4 & $\mathrm{B}-\mathrm{C}$ & Kirov mine & 85.5 & 6.1 & 1.1 & 0.3 & 7.0 & 0.86 \\
\hline KB5 & B-C & Raspadskii open-pit mine & 86.7 & 5.5 & 1.1 & 1.2 & 5.5 & 0.76 \\
\hline KB6 & $\mathrm{B}-\mathrm{C}$ & Erunakovskaya mine & 87.5 & 5.6 & 0.9 & 0.5 & 5.5 & 0.77 \\
\hline KB7 & B-A & OOO Uchastok Koksovyi mine & 90.0 & 4.6 & 2.0 & 1.4 & 2.0 & 0.61 \\
\hline KB8 & $\mathrm{B}-\mathrm{B}$ & OOO Uchastok Koksovyi mine & 89.6 & 4.8 & 1.9 & 0.3 & 3.4 & 0.64 \\
\hline KB11 & $\mathrm{B}-\mathrm{C}$ & Belovo mine & 86.0 & 5.8 & 2.7 & 0.5 & 5.0 & 0.81 \\
\hline \multicolumn{9}{|c|}{ Coals from Basins of Republic Mongolia } \\
\hline RM1 & $\mathrm{L}$ & Baganuur & 70.9 & 5.2 & 1.0 & 0.5 & 22.4 & 0.88 \\
\hline RM2 & S-B & Shive Ovoo & 73.1 & 4.3 & 1.0 & 0.9 & 20.7 & 0.71 \\
\hline RM3 & $\mathrm{B}-\mathrm{C}$ & Nariin Sukhait & 84.4 & 4.7 & 1.6 & 1.0 & 8.3 & 0.67 \\
\hline RM4 & B-B & Tavantolgoi & 87.8 & 5.2 & 1. & 0.4 & 5.4 & 0.71 \\
\hline
\end{tabular}

Source: ISO, 2005

Notation: L- lignite (brown coal); S-B - subbituminous coal; B-C- bituminous of C grade;

B-B- bituminous of B grade; B-A- bituminous of A grade

Table 2. Results of proximate analysis and the physicochemical characteristics and conversions of coals from different Coal Basins

\begin{tabular}{|c|c|c|c|c|c|c|c|}
\hline Coal code & $\mathbf{A}^{\mathbf{d}}, \mathbf{w t .} \%$ & $\mathbf{V}^{\mathbf{d a f}}, \mathbf{w t} \boldsymbol{\%}$ & $\mathbf{R}_{\mathbf{0}, \mathbf{r}}, \boldsymbol{\%}$ & $\mathbf{V}_{\mathbf{t}}, \boldsymbol{\%}$ & $\mathbf{y}^{\mathbf{*}}, \mathbf{~ m m}$ & $\mathbf{T}_{\mathbf{m a x}}{ }^{\mathbf{0}} \mathbf{C}$ & $\begin{array}{c}\text { Coal } \\
\text { conversion, }\end{array}$ \\
\hline ES1 & 7.7 & 44.8 & 0.43 & 80 & 0 & 447 & 34 \\
\hline ES2 & 6.5 & 44.7 & 0.47 & 73 & 0 & 441 & 25 \\
\hline ES3 & 18.7 & 45.5 & 0.56 & 81 & 0 & 452 & 35 \\
\hline ES4 & 7.5 & 44.0 & 0.61 & 79 & 10 & - & 45 \\
\hline RT1 & 8.2 & 45.2 & 0.66 & 82 & 15 & 451 & 46 \\
\hline RT2 & 5.6 & 35.8 & 0.77 & 85 & 21 & 478 & 69 \\
\hline KB1 & 5.7 & 42.3 & 0.71 & 96 & 10 & 459 & 70 \\
\hline KB2 & 3.4 & 38.7 & 0.80 & 85 & 18 & 467 & 83 \\
\hline KB3 & 6.3 & 38.7 & 0.91 & 87 & 25 & 466 & 86 \\
\hline KB4 & 3.8 & 40.6 & 0.68 & 93 & 24 & 456 & 77 \\
\hline KB5 & 9.6 & 38.4 & 0.85 & 80 & 18 & 466 & 86 \\
\hline KB6 & 11.2 & 34.5 & 0.93 & 82 & 30 & 481 & 69 \\
\hline KB7 & 7.0 & 19.4 & 1.47 & 61 & 13 & 510 & 14 \\
\hline KB8 & 6.1 & 20.6 & 1.41 & 60 & 9 & 501 & 12 \\
\hline
\end{tabular}




\begin{tabular}{|l|c|c|c|c|c|c|c|}
\hline KB11 & 25.9 & 36.3 & 0.80 & 78 & 24 & & 69 \\
\hline RM1 & 5.1 & 44.7 & 0.41 & 73 & 0 & 437 & 27 \\
\hline RM2 & 18.7 & 44.8 & 0.46 & 71 & 0 & 438 & 14 \\
\hline RM3 & 6.8 & 36.1 & 0.74 & 80 & 10 & 477 & 67 \\
\hline RM4 & 8.2 & 27.7 & 1.12 & 79 & 16 & 490 & 54 \\
\hline
\end{tabular}

Thickness of plastic layer

\subsection{Thermal Decomposition of Coals}

The coal dissolution in the solvent media is considered to occur via thermal cleavage of the chemical bonds in the coal organic matter. It is an interesting issue that how the reactivity of coal during dissolution in the antracene oil solvent relates to its thermal stability.

TG-DTG analysis showed that the initial decomposition of low-rank coals with little loss of the volatile substances was observed at Tinit of near 320$350^{\circ} \mathrm{C}$, and of high-rank bituminous coals did at 430$450^{\circ} \mathrm{C}$ Figure 1 . The main thermal decomposition stage with the highest weight loss rate occurred at temperatures above $430-440^{\circ} \mathrm{C}$ up to $520^{\circ} \mathrm{C}$ depending on the coal samples.

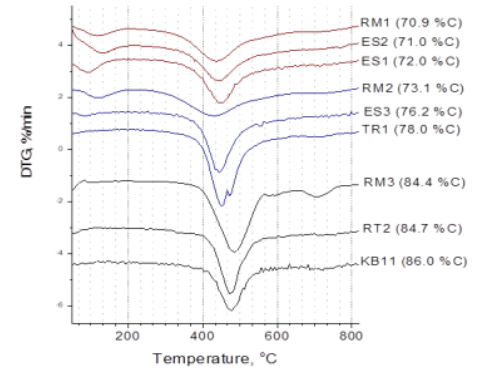

Figure 1. DTG curves for the representative coal samples

The increase in the rank of coal (quantified by carbon content) resulted in an increase both in $\mathrm{T}_{\text {init }}$ temperature at which the initial decomposition commenced and in $\mathrm{T}_{\max }$ temperature at which the extensive decomposition was observed with maximal weight loss rate.

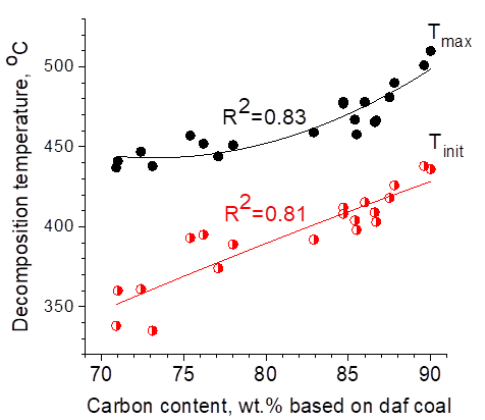

Figure 2. $\mathrm{T}_{\max }$ and $\mathrm{T}_{\text {init }}$ values for coals as a function of carbon content
The dependences shown in Figure 2 are described by a non-linear regression with a fairly high $\mathrm{R}^{2}$ determination coefficient $(0.83$ and 0.81$)$. Based on these results, the $\mathrm{T}_{\text {init }}$ and $\mathrm{T}_{\max }$ temperatures can be considered as a characteristic coal property that reflects thermal stability. The $\mathrm{T}_{\max }$ values thus obtained were included in Table 2.

\subsection{Thermal Dissolution of Coals}

\subsubsection{Temperature Effect on Coal Dissolution}

The effect of temperature on the dissolution of the selected coals was studied to find the optimal temperature reaction conditions. When KBB11 bituminous coal (Table 1) was extracted with a hot anthracene oil at $105^{\circ} \mathrm{C}$, the yield of solubles increased with the extraction time; the yield of quinoline-solubles attained $14 \%$ in two weeks Figure 3.

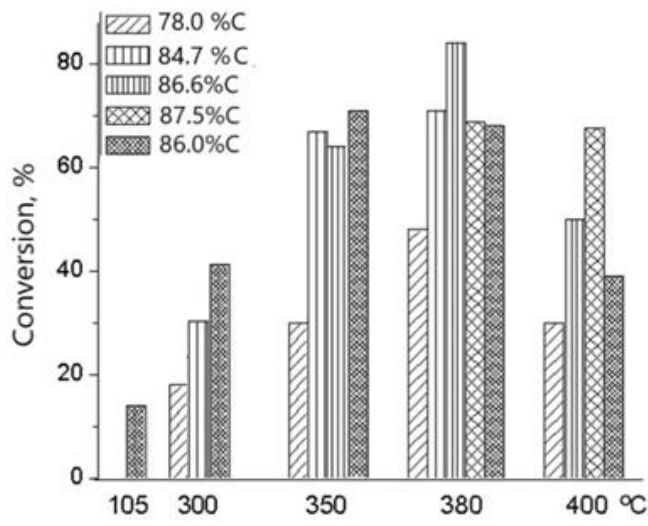

Figure 3. The degree of coal conversion into quinoline solubles versus the reaction temperature

As the temperature increased to $300^{\circ} \mathrm{C}$, the yield reached $41 \%$ in an hour and changed only slightly $(42 \%)$ in $3 \mathrm{~h}$ extraction. A considerable increase in the yield of the quinoline-solubles was observed at $350^{\circ} \mathrm{C}$, and changed only slightly at a higher temperature of $380^{\circ} \mathrm{C}$. Further increase in temperature to $400^{\circ} \mathrm{C}$ resulted in a sharp decrease in coal dissolution. This can result from the intensification of the secondary poly condensation reactions of the resulting reactive soluble substances 
with the formation of insoluble matter. All other tested coals showed a similar extremal trend of conversion versus the reaction temperature. It is of importance to note that the effective dissolution of the reactive coals occurred at a fairly low temperature of $350-380^{\circ} \mathrm{C}$, significantly lower than that of thermal decomposition. This can indicate that, in addition to the specific thermal cleavage effect, the AO solvolysis of chemical bonds in the coal matter facilitated its conversion into soluble products.

Coal dissolution under the studied conditions resulted in the selective formation of predominantly quinoline-soluble substances. The resulting main products removed from the autoclave with a yield of at least $97 \%$ represented solid pitch-like matter consisted of dissolved coal, non-dissolved coal residue with little ash, and solvent. The yield of gases at $380^{\circ} \mathrm{C}$ was less than $0.5 \%$. The gaseous products obtained from the bituminous coals consisted of mainly $\mathrm{CO}_{2}$ with fewer amounts of $\mathrm{H}_{2} \mathrm{~S}, \mathrm{H}_{2}, \mathrm{CH}_{4}$, and much less $\mathrm{CO}$.

\subsubsection{Coal Dissolution vs Coal Properties, Correlation Analysis}

Taking account of the results above, a comparison of the reactivity of all the selected coal samples in dissolution reaction was carried out at the optimal temperature of $380^{\circ} \mathrm{C}$ for $1 \mathrm{~h}$ using $\mathrm{AO}$ as a solvent. The data obtained are displayed in Table 2.

One can see from Table 2 that the reactivity of coal samples differed greatly, the conversion degree ranged from $12 \%$ to $86 \%$.

Figure 4 shows graphical dependences of conversion on the main classification characteristics of coals. The extremal dependencies exist between the conversion and $\mathrm{C}^{\text {daf }}$ carbon content, $V^{\text {daf }}$ volatile matter yield, $R_{o, r}$ vitrinite reflectance, and $T_{\max }$, in contrast to the trend in the thermal decomposition. The coals with $\mathrm{C}^{\text {daf }}$ of about $85 \%$ have maximum conversion in accordance with that reported by Iino et al. [10].

The correlations were analyzed, and the mode of regression equations with the determination coefficients are displayed in Table 3.

The most intimate relationships were found between the conversion and vitrinite reflectance Ro,r (which is a reliable indicator of the polyaromatic clusters in coals) and the temperature of maximum coal decomposition on pyrolysis (Figures $4 \mathrm{c}$ and $4 \mathrm{~d}$, respectively).

Table 3. Determination coefficients of correlations between the conversion and characteristics of coal properties

\begin{tabular}{|c|c|c|c|}
\hline Analytical parameter & Unit of measure & Function, order of regression & $R^{2}$ \\
\hline \multirow[t]{2}{*}{ Carbon content } & wt $\%$ on a daf basis & Polynomial, 2 & 0.57 \\
\hline & & Polynomial, 3 & 0.88 \\
\hline \multirow[t]{3}{*}{ Hydrogen content } & wt $\%$ on a daf basis & Linear & 0.44 \\
\hline & & Polynomial, 2 & 0.43 \\
\hline & & Polynomial, 3 & 0.49 \\
\hline \multirow[t]{2}{*}{ Oxygen content } & wt $\%$ on a daf basis & Polynomial, 2 & 0.48 \\
\hline & & Polynomial, 3 & 0.77 \\
\hline \multirow[t]{2}{*}{$\mathbf{H} / \mathbf{C}$} & atomic ratio & Polynomial, 2 & 0.34 \\
\hline & & Polynomial, 3 & 0.36 \\
\hline \multirow[t]{2}{*}{$\mathrm{O} / \mathrm{C}$} & atomic ratio & Polynomial, 2 & 0.42 \\
\hline & & Polynomial, 3 & 0.77 \\
\hline \multirow[t]{2}{*}{ Yield of volatile matter } & wt $\%$ on a daf basis & Polynomial, 2 & 0.78 \\
\hline & & Polynomial, 3 & 0.82 \\
\hline \multirow[t]{3}{*}{ Vitrinite content } & $\%$ & Linear & 0.61 \\
\hline & & Polynomial, 2 & 0.63 \\
\hline & & Polynomial, 3 & 0.71 \\
\hline \multirow[t]{3}{*}{ Vitrinite reflectance, $R_{o, r}$} & $\%$ & Polynomial, 2 & 0.85 \\
\hline & & Polynomial, 3 & 0.85 \\
\hline & & Gaussian & 0.92 \\
\hline Temperature, $T_{\max }$ & ${ }^{\circ} \mathrm{C}$ & Gaussian & 0.92 \\
\hline Plastic layer thickness & $\mathrm{mm}$ & Linear & 0.51 \\
\hline
\end{tabular}



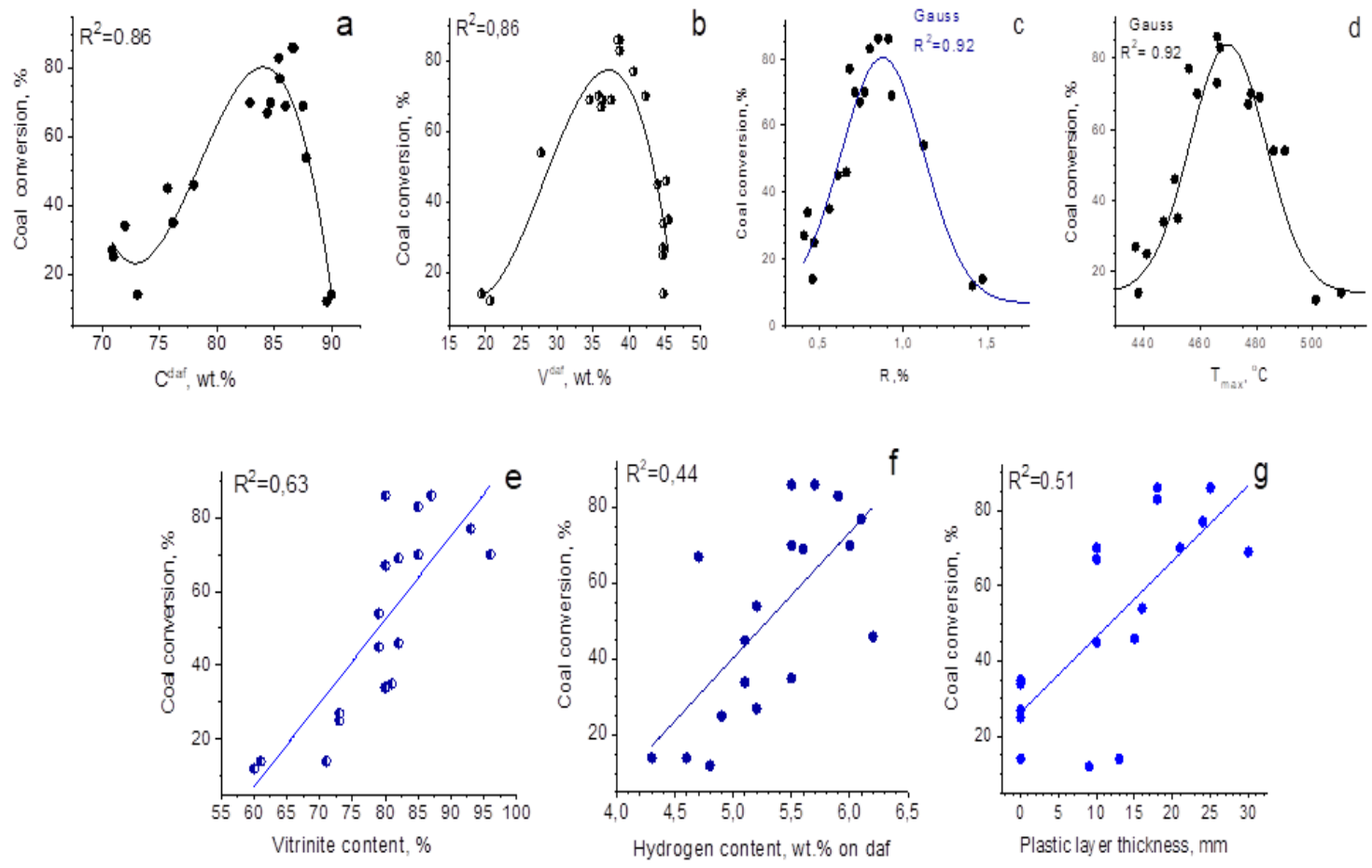

Figure 4. Relationships between the conversion of coals on thermal dissolution and characteristics of their composition and chemico-technological properties

These relationships are best described by the symmetric Gaussian function (determination coefficient $\mathrm{R}^{2}=0.92$ ). It should be noted that the $\mathrm{R}_{\mathrm{o}, \mathrm{r}}$ index reflects the properties of the vitrinite component only. Since the petrographic components differ significantly with their reactivities, the prognostic index $R_{\mathrm{o}, \mathrm{r}}$ can be applied to vitrinite-type coals only. In our samples, the vitrinite content was more than $70 \%$ (except for two samples with a content of $60 \%$, Table 2), and the data in Figure 4e show that conversion increases with increasing its content; when describing the dependence by the linear regression equation, the correlation coefficient was $R=0.78$.

Many chemical and technological properties of coals are associated with the contents of hydrogen and oxygen [20]. Figure $4 \mathrm{f}$ shows a general trend to increase in coal conversion with an increase in the $\mathrm{H}^{\text {daf }}$ hydrogen content, however, the correlation level is low $\left(\mathrm{R}^{2}=0.44\right)$. The weak correlation can be due to the fact that the process under consideration is not associated with the deep destruction of organic matter of coals to low molecular weight products that consume a significant amount of hydrogen. The data obtained also showed a complex conversion dependence on the oxygen content. The lowest conversion was observed for high-ranked coals with low oxygen content and for brown coals with the largest oxygen content, while the general dependence for the whole rank of coals is characterized by low determination coefficients $\left(\mathrm{R}^{2}=0.42\right.$ and 0.77 for polynomials of the second and third orders, respectively).

The relationship between the conversion and the plastometric properties of coals was also analyzed. The plastic layer thickness $(\mathrm{y}, \mathrm{mm})$ was used as a factor for this analysis. The data in Figure $4 \mathrm{~g}$ indicate that although there is some scatter, the general trend is evident: non-coking coals have a low conversion, and coking coals showed a tendency to increase the conversion with the increase in the plastic layer thickness. The overall correlation coefficient for the linear regression equation is $R^{2}=0.51(R=0.71)$. As noted above, a similar level of correlation was also observed with the softening point $[13,14]$. It can be assumed that the plastic matter in coals facilitates their thermal dissolution, the poor correlation seems to be due to the effect of other independent characteristics of the properties of coals on the process of thermal dissolution. 
Thus, we can summarize that the conversion of coals upon thermal dissolution in the anthracene oil at low temperature is certainly related to their classification parameters, such as $\mathrm{C}^{\mathrm{daf}}, \mathrm{V}^{\mathrm{daf}}, \mathrm{R}_{\mathrm{o}, \mathrm{r}}, \mathrm{T}_{\max }$, and plastic layer thickness. Medium-rank coking coals, which are capable of releasing plastic matter on heating, exhibited a maximum degree of conversion. Based on the correlation analysis, the optimal characteristics of the properties of coals were quantified to ensure their effective conversion into the quinoline-soluble products. Shown in Table 4 are the optimized indexes which can serve as criteria for the selection of the most suitable coal for the production of quinoline-soluble substances by using the thermal dissolution process. It can be noted that most of these indicators are intended to characterize coal as raw material for semicoking and coking. The data obtained show, however, that they can be used successfully also to assess the dissolution capacity of coals.

Table 4. The properties of coals preferred to the thermal dissolution to obtain quinoline-solubles

\begin{tabular}{|l|l|}
\hline Property & Optimal value \\
\hline Carbon content, $\mathbf{C}^{\text {daf }}, \mathbf{w t} \%$ & $83-86$ \\
\hline $\begin{array}{l}\text { Yield of volatile matter, } \mathbf{V}^{\text {daf }} \\
\text { wt \% }\end{array}$ & $35-39$ \\
\hline Vitrinite content, \% & $>70$ \\
\hline Vitrinite reflectance, $\mathbf{R}_{\mathbf{o}, \mathbf{r}}, \boldsymbol{\%}$ & $0.80-0.90$ \\
\hline $\begin{array}{l}\text { Temperature of the main stage } \\
\text { at pyrolysis, }{ }^{\circ} \mathbf{C}\end{array}$ & $465-475$ \\
\hline Plastic layer thickness, $\mathbf{~ m m}$ & $\begin{array}{c}17-25 \\
\text { preferably }\end{array}$ \\
\hline
\end{tabular}

\subsubsection{The Characterization of the Extract Products}

The resulting main products obtained from different coals were classified in terms of the toluene insolubles ( $\alpha$-fraction), quinoline insolubles $\left(\alpha_{1}\right.$ fraction), and toluene insolubles but quinoline soluble fraction ( $\alpha_{2}$-fraction). Figure 5 shows that the proportion of the $\alpha$-fraction decreased, but the $\alpha_{2}$ fraction significantly increased as coal dissolution progressed, i.e. as coal reactivity increased. The $\alpha_{2}$ fraction in pitches is known to be the most valuable constituent in terms of binding properties. Thus, one can expect that high-quality binding matter can be produced from the dissolution of the reactive bituminous coals.

The extracts obtained from the dissolution of bituminous TR1, TRB2, KBB6, and KBB7 coals consisted of a complex mix of mostly aromatic species. Their chemical composition was as follows, wt.\%: $\mathrm{C} 89.2-90.0, \mathrm{H} 5.4-5.5$, the $\mathrm{H} / \mathrm{C}$ atomic ratio from 0.74 to 0.71 (Table 5).

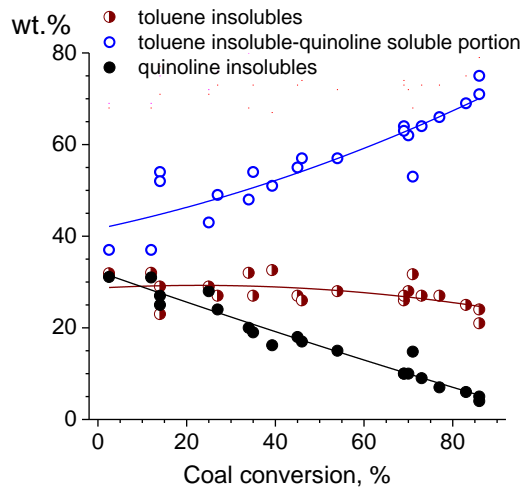

Figure 5. The variation in group composition of the products obtained during coal dissolution as a function of coal conversion.

The contents of nitrogen, sulphur and oxygen ranged $1.4 \%$ to $1.9 \%$, sulphur $0.6 \%$ to $1.1 \%$ and oxygen $1.9 \%$ to $3.2 \%$ depending on the coal type. The pitchlike matter of the product had $\mathrm{T}_{\text {soft }}$ softening point of 76 to $96^{\circ} \mathrm{C}$.

Table 5. Chemical composition of the extract obtained from bituminous coals at $380^{\circ} \mathrm{C}$

\begin{tabular}{|c|c|c|c|c|c|c|c|}
\hline \multirow{2}{*}{$\begin{array}{l}\text { Coal } \\
\text { used }\end{array}$} & \multicolumn{5}{|c|}{ wt. \% } & \multirow{2}{*}{$\begin{array}{c}\mathbf{H} / \mathbf{C} \\
\text { at }\end{array}$} & \multirow{2}{*}{$\begin{array}{c}\mathbf{T}_{\text {soft softening }} \\
\text { point, }{ }^{\circ} \mathrm{C}\end{array}$} \\
\hline & $\mathrm{C}$ & H & $\mathbf{N}$ & $\mathbf{S}$ & O & & \\
\hline TRB1 & 89.2 & 5.5 & 1.4 & 0.7 & 3.2 & 0.74 & 96 \\
\hline TRB2 & 89.8 & 5.5 & 1.4 & 0.8 & 2.5 & 0.73 & 76 \\
\hline KBB6 & 89.9 & 5.4 & 1.9 & 0.6 & 2.2 & 0.72 & 81 \\
\hline KBB7 & 90.0 & 5.3 & 1.7 & 1.1 & 1.9 & 0.71 & 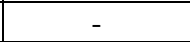 \\
\hline
\end{tabular}
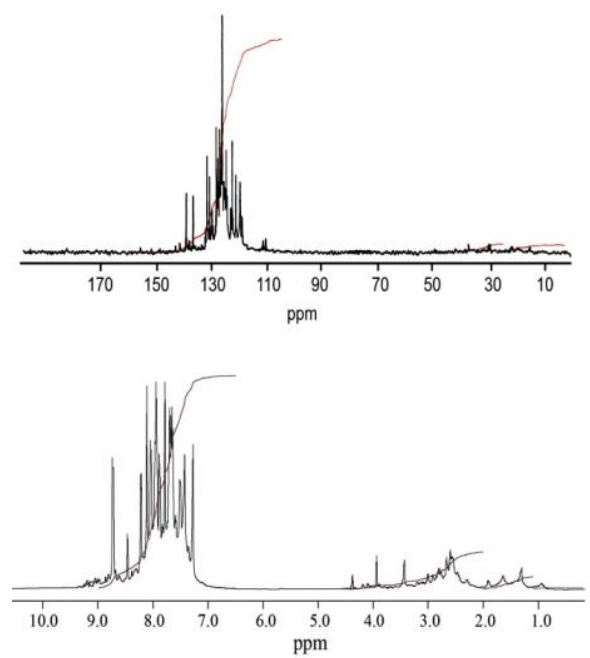

Figure 6. ${ }^{1} \mathrm{H}$ and ${ }^{13} \mathrm{C}$ NMR spectra of the chloroform-soluble substances of the extract obtained by thermal dissolution of KKB6 bituminous coal 
Displayed in Figure 6 are the ${ }^{13} \mathrm{C}$ and ${ }^{1} \mathrm{H}$ NMR spectra for the chloroform-soluble fraction of the extract obtained from the KBB 6 coal at $380^{\circ} \mathrm{C}$. Both spectra indicate the highly aromatic nature of the extracted matter.

The Brown-Ladner structural parameters [21] estimated from the ${ }^{1} \mathrm{H}$ NMR spectra are shown in Table 6. One can see that the chloroform-solubles consisted of predominantly aromatic molecules with the aromatic rings rarely substituted with short alkyl groups (mainly methyl and ethyl). Comparing the $\mathrm{H}_{\mathrm{aru}} / \mathrm{C}_{\mathrm{ar}}$ indexes for the extract and $\mathrm{AO}$ solvent, it should be noted that the average aromatic nuclei of the extract molecules consisted of 3-4 condensed rings, and that of AO molecules did 3 aromatic rings. This may imply that the aromatic molecules extracted from the coal matter have a larger condensation degree.

Table 6. The Brow-Ladner structural parameters of the average molecule of the chloroform soluble fraction from the coal extracts obtained on the dissolution of KKB6 bituminous coal in $\mathrm{AO}$ at $380^{\circ} \mathrm{C}$

\begin{tabular}{|l|c|c|c|c|}
\hline $\begin{array}{l}\text { AO solvent, } \\
\text { extract }\end{array}$ & $\boldsymbol{f}_{\boldsymbol{a}}$ & $\mathbf{H}_{\text {aru }} / \mathbf{C}_{\mathbf{a r}}$ & $\boldsymbol{\sigma}$ & $\mathbf{n}$ \\
\hline AO & 0,94 & 0,74 & 0,15 & 1,24 \\
\hline Extract & 0.92 & 0.69 & 0.12 & 1.53 \\
\hline
\end{tabular}

Notation:

$\mathrm{f}_{\mathrm{a}}$-aromaticity;

$\mathrm{H}_{\mathrm{aru}} / \mathrm{C}_{\mathrm{ar}}$ ratio reflects the extent of aromatic rings condensation; $\sigma-$ aromatic ring substitution;

$\mathrm{n}$ - parameter reflecting the number of carbon atoms in the alkyl substituents.

\section{CONCLUSION}

The reactivity of a large set of different-ranked coals for thermal decomposition decreases continuously as coal rank increases. Both the $\mathrm{T}_{\text {init }}$ temperature when coal pyrolysis commenced and the $\mathrm{T}_{\max }$ temperature of most extensive thermal decomposition with the maximum weight loss rate was found to correlate well with the coal rank estimated by $\mathrm{C}^{\text {daf }}$ content.

In contrast to coal pyrolysis behavior, the reactivity of coal for dissolution with the anthracene oil is an extremal function of the main classification coal indexes. The most reliable characteristics of the properties which can be used to predict the conversion of coals on dissolution were found to be the $R_{o, r}$ vitrinite reflectance, $V^{\text {daf }}$ yield of volatile matter, $C^{\text {daf }}$ carbon content, and $\mathrm{T}_{\max }$ temperature. The correlations with $R_{o, r}$ and $T_{\max }$ were best simulated by symmetric Gaussian function (with the determination coefficient of $\mathrm{R}^{2}=0.92$ in both cases).

The presence of plastic substances in the coal matter is also an important factor ensuring effective coal dissolution, coking coals showed a tendency to increase the conversion with the increase in the plastic layer thickness. Under the conditions studied, the variations in the hydrogen and oxygen contents of coals weakly reflected their ability to form quinolinesoluble substances.

The medium-ranked bituminous coals showed the highest reactivity for dissolution into the quinoline solubles, the effective dissolution occurring at a fairly low temperature of $350-380^{\circ} \mathrm{C}$, significantly lower than that of thermal decomposition. This can indicate that, in addition to specific thermal cleavage of the chemical bonds, their solvolysis by the anthracene oil facilitated coal conversion into the soluble products. One can assume coal dissolution in the anthracene oil solvent at low temperature to occur mostly through depolymerization of the coal's organic matter via thermal solvolysis of the weak $\mathrm{C}-\mathrm{C}$ and $\mathrm{C}-\mathrm{O}$ linkages between the large polyaromatic fragments [18]. The optimal characteristics of the properties of coals were quantified based on the correlation analysis to ensure the effective conversion into the quinoline-soluble products. The optimized indexes suggested can serve as criteria for the selection of the most suitable coal for the production of quinolinesoluble substances by using the coal dissolution process and the anthracene oil as a solvent.

The coal dissolution in the anthracene oil proceeded selectively with the predominant formation of the quinoline-soluble substances and little gases. The resulting extracts represented solid pitch-like matter with the softening points of 76 to $96^{\circ} \mathrm{C}$. They consisted of predominantly polycondensed aromatic molecules consisted of 3-4 condensed rings rarely substituted with short alkyl groups (mainly methyl and ethyl). The extract obtained can serve as an alternative source for aromatic chemicals, liquid fuels and as a feedstock for the production of a substitute for coal-tar pitch and for other purposes.

\section{ACKNOWLEDGMENT}

This work was supported by the Russian Foundation for Basic Research (grant no. 19-5344001) and the Mongolian Science and Technology Foundation (grant no. SHUGH/OHU/- 2019/13) and also within the framework of the project no. AAAAA17-117021310220-0) a state contract at the Institute 
of Chemistry and Chemical Technology, Siberian Branch, Russian Academy of Sciences, and at the Institute of Chemistry and Chemical Technology of the Mongolian Academy of Sciences.

Analytical data were obtained using the equipment of the Krasnoyarsk Regional Center of Collective Use of the Krasnoyarsk Science Center of the Siberian Branch of the Russian Academy of Sciences, and of the Center of Collective Use of the Institute of Coal Chemistry and Chemical Materials Science of the Federal Research Center of the Siberian Branch of the Russian Academy of Sciences, Kemerovo.

\section{REFERENCES}

[1] Babich A., Senk D., Coke in the iron and steel industry. In: I. Suarez-Ruiz, F. Rubiera, M.A. Diez (Eds.)., (2014) New Trends in Coal Conversion: Combustion, Gasification, Emissions, and Coking, Woodhead Publishing Cambridge, United States, 367-404. 10.1016/B978-0-08-102201-6.00013-3

[2] Tiwari H.P., Saxena V.K., (2019) Industrial perspective of the cokemaking technologies. In: I. Suarez-Ruiz, F. Rubiera, M.A. Diez (Eds.), New Trends in Coal Conversion: Combustion, Gasification, Emissions, and Coking, Woodhead Publishing, Cambridge, United States, 203-246. DOI: 10.1016/B978-0-08-102201-6.00008-X

[3] World Steel in Figures (2019) Now Available [Electronic resources]. URL: https://www.worldsteel.org/media-centre/pressreleases/2019/world-steel-in-figures-2019 (Accessed 15.09.2020)

[4] Granda M., Blanco C., Alvarez P., Patrick J.W., Menendez R., (2014) Chemicals from coal coking, Chemical Review, Vol. 114, 1608-1636. DOI: $10.1021 / \mathrm{cr} 400256 \mathrm{y}$

[5] World Aluminium (2019) International Aluminium Institute. http://www.worldaluminium.org/media/filer_public. Cited July 17, 2020.

[6] Mochida I., Okuma O., Yoon S.-H., (2014) Chemicals from direct coal liquefaction. Chemical Reviews, Vol. 114, 1637.

[7] Shui H., Zhao W., Shan C., Shui T., (2014) Caking and coking properties of the thermal dissolution soluble fraction of a fat coal. Fuel Processing Technology, Vol. 118, 64.

[8] Rahman M., Pudasainee D., Gupta R., (2017) Review on chemical upgrading of coal: Production processes, potential applications and recent developments. Fuel Processing Technology, Vol. 158, 35.
[9] Kuznetsov P.N., Kuznetsova L.I., Buryukin F.A., Marakushina E.N., Frizorger V.K., (2017) Methods for the preparation of coal-tar pitch. Solid Fuel Chemistry, Vol. 49, 213. DOI: 10.3103/S0361521915040059

[10] Iino M., Takanohashi T., Ohsuga H., Toda K., (1988) Molecular and Colloidal Structure of Coal Asphaltenes and Other Heavy Solvent Soluble Components. Fuel, Vol. 67, 1639.

[11] Mochida I., Takarabe A., Takeshita K., (1979) Solvolytic Liquefaction of Coals with a series of Solvents. Fuel, Vol. 58, 17.

[12] Griffith J.M., Burgess-Clifford C.E., Rudnick L.R., Schobert H.H., (2009) Solvent Extraction of Bituminous Coals Using Light Cycle Oil. Energy Fuels, Vol. 23, 4553.

[13] Okuyama N., Komatsu N., Shigehisa T., Kaneko T., Tsuruya S., (2004) Hyper coal process to produce the ash-free coal. Fuel Processing Technology, Vol. 85, 947.

[14] Yoshida T., Li C., Takanohashi T., Matsumura A., Sato S., Saito I., (2004) Fuel Processing Technology, Vol. 86, 61.

[15] Koyano K., Takanohashi T., Saito I., (2011) Energy Fuels, Vol. 25, 2565.

[16] Sakimoto N., Koyano K., Takanohashi T., (2013) Energy Fuel, Vol. 27, 6594.

[17] Kuznetsov P. N., Perminov N. V., Kuznetsova L. I., Buryukin F. A., Kolesnikova S. M., Kamenskii E. S., Pavlenko N. I., (2020) Thermal dissolution of different-ranked coals in tetralin and the anthracene fraction of coking tar // Solid Fuel Chemistry, Vol. 54, 61-68.

[18] Kuznetsov P.N., Kamenskiy E.S., Kuznetsova L.I., (2020) ACS Omega, Vol. 5, 1133.

[19] Kuznetsov P. N., Budeebazar Avid., Fan Xing., Perminov N.V., Kuznetsova L.I., Korolkova I. V., (2020) Thermal Dissolution of Bituminous Coal in Heavy Coal Semicoking Tar and in Binary Blends with the Anthracene Oil //Journal of Siberian Federal University. Engineering \& Technologies Vol. 13, 1018-1027. DOI: 10.17516/1999-494X028211

[20] Speight James G., (2015) Hand Book of Coal Analysis. Second edition. John Wiley and Sons. Inc.

[21] Bartle K. D., Jones D. W., (1978) Nuclear Magnetic Resonance Spectroscopy. In Analytical Methods for Coal and Coal Products, Vol. 2, 103-160. 1st ed.; Karr, C., Jr.; Academic Press: New York, DOI: 10.1016/B978-0-12-399902-3.50010-5. 